\title{
Pragmatics of Negation in Relation to Political Discourse on the Brexit Referendum
}

Alham fadhl Muslah*

College of Physical Education and Sports Sciences, University of Diyala /ELTE University

DOI: $\underline{10.36348 / \text { sijll.2020.v03i04.003 }}$ | Received: 24.03.2020 | Accepted: 01.04.2020 | Published: 09.04.2020

*Corresponding author: Alham fadhl Muslah

\section{Abstract}

This study is intended to analyse the phenomenon of negation and the use of pragmatic strategies in two speeches given by Prime Ministers David Cameron and Theresa May before and after the historic Brexit referendum[22]. This study is intended to achieve the following objectives: (a) to investigate the types of negative forms used by two former British prime ministers in two of their speeches; (b) to understand the impact of gender and ideology on the types of negation in political speech; and (c) to examine the impact of certain pragmatic strategies used by two people of different genders within the scope of the phenomenon of negation in building meaning in political discourse. Furthermore, the nature of the study follows the cognitive-social approach. As such, the researcher adopted the social-cognitive model by Van Dijk [1] for the data analysis which will take a quantitative form. The first stage of the analysis is an investigation of the frequency and type of negation used in the two speeches by people of differing genders who were leaders at different times. The second stage examines five pragmatic strategies within the scope of negation to discover the impact of the relationship between knowledge and power as the two prime ministers put their ideas into practice. The results obtained show that the practical effects of political character when using different types of negation do not depend on the variable of gender as much as on the subjective ideology and on whether the context of political discourse can be exploited through the expression of denial or dissatisfaction regarding a specific issue.

Keywords: negation, brexit, presupposition, speech acts, power.

Copyright @ 2020: This is an open-access article distributed under the terms of the Creative Commons Attribution license which permits unrestricted use, distribution, and reproduction in any medium for non-commercial use (NonCommercial, or CC-BY-NC) provided the original author and source are credited.

\section{INTRODUCTION}

Negation is a complex linguistic phenomenon, since it produces more rhetorical and stylistic effects than a positive scenario might do in the same circumstances. Many scholars have investigated the classification and types of negation that depend on diachronic and synchronic studies by, for example, Jespersen [2], Zimmer [3], and Horn [4]. Though the subject of negative analysis has taken a central stage in the works of many logicians, philosophers, and linguists, the study of English negative variations and ambiguity still needs to be examined from positions other than the levels of grammar. Thus, many investigators have studied negative expressions from the perspective of psychological investigation and pragmatics. Since 1990, linguists have begun to focus on the relationship between politics and the phenomenon of language. Chilton and Schäffer [5] suggested that language is the instrument used to carry out any political or social activity. Any communication has a sender, message, and receiver, and one can (with the help of linguistic clues and social knowledge) decode the message. This paper aims to examine the phenomenon of negation and the pragmatic perspectives with regard to the case of former British Prime Minister Cameron's (prereferendum) and May's (post referendum) speeches, to discover the role of the gender variable in the value of negation on the one hand, and the impact of the relationship between knowledge and power when politicians apply their ideas by testing five pragmatic strategies on the other.

\section{LITERATURE REVIEW}

Evans and Green [6] state that through cognitive linguistics "Language offers a window into a cognitive function, providing insights into the nature, structure, and organization of thoughts and ideas." In other words, it focuses mainly on the relationship between the language and the human. It rejects the concept of studying languages in separate disciplines (syntax, semantics, and pragmatics) as generative grammar introduced by Noam Chomsky [7]. Negation is part of this story. All natural languages 
have their own linguistic devices to show denial or dissatisfaction in specific situations in everyday communication. However, the context of negative utterances can play a vital role in the speaker's choice of type of negatives and the interpretation of these utterances in the mind of the listener. The situation is not different in politics, since any political activity is dependent primarily on language. One feature of political discourse is that it is a communicative activity, for example an inauguration speech or a debate, that depends on the relationship between speaker and listener. However, the achievement of a political aim beyond any speech is no more primarily dependent on the selection of vocabulary than on its effect on the audience, and this is the function of pragmatics- to achieve the intentional message. Linguists such as Fairclough [8] and Van [1] further argued that pragmatic analysis of any discourse would be affected by social and cognitive factors. Langtoz [9] stated that "being sensitive to the cultural norms of particular social-communicative environments - and corresponding discourses-humans can place their interlocutors into meaningful contexts that contribute to their cognitive growth and survival. Therefore, the individual's ideology, knowledge, and social norms reveal their language and role in society.

\section{Negation in the English Language}

Generally, there are two types of negation in English; explicit negative words such as the not, never, no, and but conjunctions and implicit negative words, all what can express negativity [10]. Arimitsu [11] observed that "the concept against positive is not fixed."

\section{Explicit Negation}

It is the case where a negative word like 'not' is explicitly used as in the following example:

\section{(1) Henry is not a good man.}

\section{Implicit Negation}

Many linguistic strategies can achieve this type of negation. In example (2), the word spinster implicitly expresses a feature of negation in its meaning (i.e., not married):

(2) She is a spinster.

\section{Affixal Negation}

Zimmer [3], Funk [12], and Bybee [13] stated that there are some English prefixes such as un-, im-, and in- that can reflect contrary and contradictory interpretations as part of words (adjective or verb), as the following example shows:

(3) It is impossible to pass the exam.

\section{Implicit Negative Adverbs and Quantifiers}

Leech [14] argued that "there are adverbs and determiners which are negative in meaning, but not in form (e.g., barely, few, little, rarely, scarcely, seldom), as they are followed by non-assertive forms, in addition, the sentences in which they appear generally require positive tag questions." For example:

\section{(4) I rarely visit my family.}

The word only, which can be used as an adjective and an adverb, is to some extent capable of negating a sentence implicitly, where it can be followed by a non-assertive item such as any $[15,16]$.

\section{Conditional clauses expressing implicit negation}

A conditional clause is another linguistic strategy that can easily convey the meaning of implicit negation, owing to the fact that the achievement of a condition in a conditional is related to a specific situation. For instance:

(5) If John gets a scholarship in France, I am certainly travelling with him.

Graver [17] adds that "it is important to note that the probability of the condition being fulfilled often exists in the speaker's mind."

\section{Negative Contexts}

Ota $[18,11]$ suggested that "NPIs such as any, yet, lift a finger, comparative context, and until, etc., appear as a characteristic in a negative context."

\section{Negation in Pragmatics}

Some utterances can, in particular contexts, convey implicit negation in the deep meaning through irony $\left.{ }^{1}\right]$. In example (6), the coach's judgement (he's a skilful player) is ironic. The sentence is explicitly positive in structure, but it shows some implicit negation in the deep meaning being expressed (he is a stupid player!).

(6) John fails to score a simple goal. The coach says he is a skilful player!

\section{RESEARCH METHOD}

In order to achieve the main aim of the present study which is to investigate the negation phenomenon in political discourse from a pragmatic perspective, the researcher adopted the social - cognitive model by Van Dijk [1] for the data analysis. Five strategies-speech acts [19], presupposition, violation of Cooperative principle [20] (henceforth: CP), off-record, and onrecord-were chosen to examine their roles in achieving the political functions within the scope of negation. The research sample included two speeches; the first was by David Cameron, and the second was by Theresa May. The quantitative method was more appropriate to the nature of the study, objectives, and data under investigation [21]. Tables are used for the purposes of achieving greater accuracy and depth with regard to the data analyzed.

\footnotetext{
${ }^{1}$ For more details, see Laura Hidalgo (2000), Negation, Text Worlds, and Discourse.
} 


\section{DATA ANALYSIS}

In the first speech, David Cameron, PM, takes responsibility for initiating the referendum, while in the second, Theresa May, who became the Prime Minister after David Cameron resigned, takes responsibility for negotiating the United Kingdom's (UK's) withdrawal from the European Union (EU; visit https://www.gov.uk for the respective speeches).

\section{Analysis of Cameron's Speech on the EU Referendum}

David Cameron, as the PrimeMminister in 2016, faced one of the greatest challenges in the modern history of the United Kingdom - the referendum concerning whether the country should leave the EU. He personally did not support the idea of leaving and explained why on many occasions. In his meeting with employers at the O2 company headquarters in Slough on February 24, 2016, he delivered his speech about the disadvantages of being outside the EU. The speech was 7, 101 words in length.

Cameron exploited more direct negatives than indirect ones (11 types out of the 17 total negatives). The use of the negative operator not was the most commonly used, while the lowest values were recorded with the negative operators no, never, but, and question. However, the comparative context appeared within almost $17.6 \%$ of the negative types; it was employed by Cameron to explain the economic benefits of staying in the single market. Table 1 illustrates all negative operators in the speech[23].

Table-1: Types of Negatives, Their Frequency, and Percentages in David Cameron's Speech

\begin{tabular}{|l|l|l|l|}
\hline Type of negation & Negative operator & Frequency & Percentage \\
\hline \multirow{5}{*}{ Direct negation } & $1-$ Not & 7 & $41 . \%$ \\
\cline { 2 - 4 } & $2-$ No & 1 & $5.8 \%$ \\
\cline { 2 - 4 } & $3-$ Never & 1 & $5.8 \%$ \\
\cline { 2 - 4 } & $4-$ Negative affixes & 1 & $5.8 \%$ \\
\cline { 2 - 4 } & $5-$ But conjunction & 1 & $5.8 \%$ \\
\hline Indirect negation & $1-$ If clause & 2 & $7.4 \%$ \\
\cline { 2 - 4 } & 2 - Expression with too & 0 & $0 \%$ \\
\cline { 2 - 4 } & 3 - Negative meaning & 0 & $0 \%$ \\
\cline { 2 - 4 } & $4-$ Comparative context & 3 & $17.6 \%$ \\
\cline { 2 - 4 } & 5 - Question & 1 & $5.8 \%$ \\
\hline Total number of negatives & & 17 & $100 \%$ \\
\hline
\end{tabular}

\section{Analysis of Theresa May's Speech on Leaving the} EU

After the British people voted to leave the EU in the historic referendum in 2016, Theresa May, as the new Prime Minister, began the process of withdrawal negotiations with the UK's EU partners. She delivered a speech to the Parliament on October 9, 2017 asking to discuss the results of the Brexit negotiations and the kind of new relationship the UK would have with the EU after leaving. The speech was 2,084 words. The total number of direct and indirect negatives was 27 . It is clear that May extensively exploited direct negatives; they comprised $81.48 \%$ of the total, while indirect negatives only constituted eight types, and comprised $18.51 \%$ of the total[24]. Table 2 illustrates all the negative operators used in the speech. It makes clear that the negative types are distributed in the speech as follows: the use of the direct negative element not which constituted $37 \%$ to become the highest average among the other negative types in the speech. The use of negative affixes came second with $22 \%$, while the direct negative elements no, but conjunction, and negative meaning showed the same low value at just $11 \%$. Similarly, both the direct negative operator but conjunction and the indirect negative operator comparative context represented the lowest rate with $3 \%$. However, the negative adverb never strategy and too did not record any value in the speech. Table 2 illustrates all the negatives operators in the speech.

Table-2: Types of Negatives, Their Frequency, and Percentages in Theresa May's Speech

\begin{tabular}{|l|l|l|l|}
\hline Type of negation & Negative operator & Frequency & Percentage \\
\hline Direct negation & $1-$ Not & 10 & $37.03 \%$ \\
\cline { 2 - 4 } & $2-$ No & 3 & $11.11 \%$ \\
\cline { 2 - 4 } & $3-$ Never & 0 & 0 \\
\cline { 2 - 4 } & $4-$ Negative affixes & 6 & $22.22 \%$ \\
\cline { 2 - 4 } & $5-$ But conjunction & 3 & $11.11 \%$ \\
\hline Indirect negation & $1-$ If clause & 1 & $3.70 \%$ \\
\cline { 2 - 4 } & 2 - Expressions with too & 0 & 0 \\
\cline { 2 - 4 } & 3 - Negative meaning & 3 & $11.11 \%$ \\
\cline { 2 - 4 } & $4-$ Comparative context & 1 & $3.70 \%$ \\
\hline & $5-$ Question & 0 & 0 \\
\hline Total number of negatives & & 27 & $100 \%$ \\
\hline
\end{tabular}




\section{Pragmatic Strategies Identified in Cameron and May's Speeches}

Cameron exploited a variety of pragmatic strategies to achieve several political aims. There were a total of 22 pragmatic strategies and they were distributed as follows: speech act had the highest average $(36.36 \%)$ amongst all the pragmatic strategies because Cameron meant to persuade the audience that it was better to stay inside the EU. In contrast, the violation of the cooperative principle strategy registered the lowest value (only 4.54\%) which indicated that Cameron was careful about what types and quantity of information he delivered to the audience with regard to the referendum's possible consequences. Both on- and off-record strategies were present to the extent of only $9.09 \%$ and $18.18 \%$, respectively; this was probably because Cameron did not want to be the direct cause for the British people voting to remaining in the $\mathrm{EU}$, at least in public; thus, he tried to offer suggestions about the advantages of staying inside a reformed EU.
Meanwhile, he demanded that the people who supported leaving the EU explain the likely economic effects of such a decision.

On the other side, May employed 22 different types of pragmatic strategies. As can be seen, among all pragmatic strategies, the speech act constitutes $50 \%$ as it is used to exhibit the important steps that the British government proposed to make them reach a good deal. This was followed by presupposition, which constituted $27.27 \%$, and was used to depict the positive scenarios of future relationships with the EU partners. In contrast, the use of on-record and violation of $\mathrm{CP}$ strategies scored the lowest values (only 4.54\%), most likely because May's speech was addressed to Parliament, and she was exhorting MPs to support her plan. The off-record strategy represented $13.63 \%$ in her speech because she needed the approval of the Parliament to achieve progress in the withdrawal process. For more details, see Table 3.

Table-3: Types of Pragmatic Strategies, their Frequencies and Percentages in Cameron's and May's Speeches

\begin{tabular}{|l|l|l|l|l|}
\hline Type of pragmatic strategy & Cameron & Percentage & May & Percentage \\
\hline Presupposition & 6 & $27 \%$ & 6 & $27.27 \%$ \\
\hline Speech act & 8 & $36.36 \%$ & 11 & $50 \%$ \\
\hline Off-record & 4 & $18.18 \%$ & 3 & $13.63 \%$ \\
\hline On-record & 2 & $9.09 \%$ & 1 & $4.54 \%$ \\
\hline Violation of CP & 1 & $4.54 \%$ & 1 & $4.54 \%$ \\
\hline Total number of pragmatic strategies & 22 & & 22 & \\
\hline
\end{tabular}

\section{DISCUSSION}

The investigation of the gender variable within negation in political discourse was one of the main objectives of the current study. Theresa May is the second most famous female British Conservative politician after Prime Minister Margret Thatcher. The statistical analysis of the negative frequencies in the two selected speeches presented in Tables 1and 2 initially shows a significant difference in the use of negatives by May; they constituted
$27(61.36 \%)$ out of a total of 44 negatives. This is a higher average than that recorded for Cameron, who used 17 $(38.63 \%)$ in total. This indicates that May believed she did what the British people expected; such arguable overconfidence led her to dismiss the voices of others and to repeat what she wanted to achieve regarding withdrawal. Table 4 illustrates the frequency of negatives in Cameron and May's speeches.

Table-4: Difference between the Frequency of Negatives in Cameron and May's Speeches

\begin{tabular}{|l|l|l|l|}
\hline Speaker & Frequency of direct negatives & Frequency of indirect negatives & Tota \\
\hline May & 19 & 8 & 27 \\
\hline Cameron & 11 & 6 & 17 \\
\hline Total & 30 & 14 & 44 \\
\hline
\end{tabular}

The frequency of negatives in May's speech to the Parliament may be explained by the fact that she did not care much about damage to anybody's character because she was pragmatically more interested in demonstrating her ability or power to attack those who objected to her withdrawal plan. On the other hand, Cameron tried to be more conservative in respect of leave voters. Generally, the use of the strong direct negative type not obtained the highest average among other direct negatives in both speeches. However, there was a significant difference in the use of this negative operator between the two speeches; it represented 17 types in Cameron's and 27 types in May's speech amongst other direct negatives. This was due to the fact that Cameron did his best not to show the impact of his position as prime minister on the vote, which he would have had in using such a strong direct negative operator. Thus, not would have emphasized the disadvantages of this historical referendum on the UK economy; he was also aware of the sensitive situation the government was in with regard to the application of the concept of democracy.

May often thought that Britain needed a strong and stable prime minister to obtain a better Brexit deal, and that the situation would be difficult if the Parliament 
were to vote against her plan. She rarely showed any mitigation strategies in her speech. By contrast, the direct negative operator but conjunction exhibited the lowest rate in both speeches. This finding may indicate that Cameron and May were clear in their ideologies and psychologically did not want to show a partial rejection or denial of some actions by using the linguistic strategy “ but-conjunction" in contrastive frames, whereby listeners could conclude cognitively that the speakers were at least partially dissatisfied about Brexit, for example in May's repeated utterance of "Brexit means Brexit." However, negative affixes were used with greater frequency in May's speech than in Cameron's (13.63\% and 2.27\%, respectively). This finding is attributed to the fact that the interpretation of negative affixes would cognitively be more abstract and local, and these phrases can only be understood in relation to the distance between the speaker and the listener. Thus, May tried not to show clarity to prompt a vaguer interpretation by the parliament of her negotiations regarding the UK's relationship with the EU after Brexit. This made the parliament doubt her plan and ultimately vote against it. Cameron seemed to be clear with his ideology, and revealed it in his outline of the disadvantages of being outside the single market.

The use of the if clause showed a very low value in both speeches (just $7.3 \%$ and $3.70 \%$, respectively), indicating that Cameron attempted not to draw up more alternative scenarios about the consequence of Brexit through the application of this linguistic strategy. Similarly, May tried to avoid applying it to give more alternative situations when trying to persuade opponents and parliament to accept her plan. Neither Cameron nor May showed any interest in the use of the linguistic strategies of question and too expression to declare their rejection or denial of Brexit, because they, as prime ministers, were obliged to accept what the British people or parliament decided.

With regard to the use of pragmatic strategies, it can be seen that both politicians employed the same frequency of pragmatic strategies. However, there were some significant differences in the ones they adopted. Firstly, May used more speech acts than did Cameron (with $25 \%$ and $18 \%$ of the total, respectively). This may have been due to the fact that the context of Cameron's speech did not provide the felicitous conditions that would enable him to perform more speech acts at the level of negation, because it was the voters who had the right to make the final decision on whether the UK would leave the EU or not. In contrast, May, as the Prime Minister after the referendum, led to the withdrawal negotiations, so the context enabled her to perform more speech acts. Cameron and May seemed to share a similar viewpoint with regard to the future consequences of Brexit. They therefore showed the same frequency of presupposition in their speeches. The same applied to off- and on-record and violation of $\mathrm{CP}$.

\section{CONCLUSION}

\section{Based on the findings, the researcher has concluded the following}

1. The interpretation of negative sentences cannot depend on the classification of negation into direct and indirect negatives. This classification may not always be an appropriate linguistic scale for determining the ambiguity of meaning in political discourse. The analysis of some indirect negatives reveals a greater complexity in understanding than direct negatives.

2. The frequency and type of negatives used by the male politician were generally fewer in number than the female politician, who used them $10 \%$ more. This significant difference in the use of negation between the two genders indicates that Cameron displayed more caution than May when discussing the disadvantages of the referendum. In terms of negative types, both genders seemed to have the same tendency to use more direct negatives then indirect negatives in their speeches.

3. Political ideology and attitudes have played a vital role in increasing or decreasing the types of negation in political discourse. As members of the Conservative Party, Cameron and May had similar ideologies and held similar attitudes towards certain domestic and international issues such as immigration and the referendum. May showed an inflexibility of character and found it difficult to accept others' attitudes or ideas. 4. The political aims beyond the pragmatic use of negation had an impact on the type and complexity of negatives. For example, the uses of affixal negatives were higher in May's speech to parliament because she aimed not to give a clear explanation of her negotiations with the EU, nor to send clear messages about them to the electorate. This was why parliament vote not to her deal.

5. The speech contexts such as time, place, and authority played a vital role in the frequency and types of negatives. The increase in their frequency in May's speech was worthy of note because she was leading negotiations. In contrast, Cameron arguably did not have any impact on the result of the referendum because the electorate itself held the right to decide whether to stay or leave the EU.

6. The findings show that both genders succeeded similarly in using pragmatic strategies within the scope of negative spaces; there were, however, some differences worth noting. May was unable to persuade the parliament to accept her Brexit plan, and this led to her resignation. Cameron displayed his wisdom by making a comparison between the consequences of staying in or leaving the EU on the British economy and employment, then handing the decision to the electorate.

7. The presupposition strategy played an important part in drawing up positive alternative scenarios to those suggested by negative utterances in the speeches. Cameron and May generally sought a balance in presupposing both positive and negative future 
consequences for the UK in terms of economics, employment, immigration, transportation, and so on. 8. Cameron exercised more caution in giving advice/orders, or displaying a particular attitude at the level of negative speech acts than May. She was bolder and delivered more commissives and directives in her speech than Cameron, who used mostly expressive speech acts. She repeated what she wanted to do-for example in her use of the famous soundbite "Brexit means Brexit" - and attacked opponents who dismissed her plans. Her inflexible character led some ministers in her government to resign, as she later did.

9. Cameron employed slightly more on- and off-record strategies in his speech than May. The power and social distance between the speaker and the audience played a vital role in employing these strategies. Cameron attempted to cultivate a close relationship between him and the audience in his speech for persuasive purposes. On the other hand, May practically tried to show that she had the power to execute the Brexit deal, and acted entirely independently of the electorate.

10. Both genders pragmatically followed the conversational principles in their speeches and reduced violations of the cooperative principle to the lowest frequency.

\section{REFERENCES}

1. Van, Dijk, T. A. (2008). Discourse and context: A socio-cognitive approach. New York, NY: Cambridge University Press.

2. Jespersen, O. (1917). Negation in English and other languages. Copenhagen: F. Host.

3. Zimmer, K. (1964). Affixal negation in English and other languages. New York, NY: Linguistic Circle of New York.

4. Horn, L. (1989). A natural history of negation. Chicago, IL: University of Chicago Press.

5. Chilton, P., \& Schäffer, C. (2003). Politics as text and talk: Analytic approaches to politic discourse. Amsterdam: John Benjamins Publishing House.

6. Evans, V., \& Green, M. (2006). Cognitive linguistics: An introduction. Mahwah, NJ, \& Edinburgh: Edinburgh University Press/Lawrence Erlbaum Associates.

7. Chomsky, N. (1968). Language and mind. New York: Harcourt Brace Jovanovich.
8. Fairclough, N. (1989). Language and Power. London: Longman.

9. Langtoz, A. (2015). Creating social orientation through language. Amsterdam: John Benjamins Publishing Company.

10. Dahl, O. (1979). Typology of sentence negation. Linguistics, 17(7), 9-10.

11. Arimitsu, N. (2000). A review on negation in positive sentences. Papers in Linguistic Science, 6, 41-60.

12. Funk, W. P. (1971). Adjectives with negative prefixes in modern English and the problem of synonymy. Zeitschrift für Anglistik und Amerikanistik, 19, 364-386.

13. Bybee, J. (1985). Morphology: A study of the relation between meaning and form. Amsterdam: John Benjamins Publishing House.

14. Leech, G. (1983). Principles of pragmatics. London: Longman.

15. Quirk, R., Greenbaum, S., Leech, G., \& Svartvik, J. (1985). A comprehensive grammar of the English language. London: Longman.

16. Dixon, R. M. W. (2005). A semantic approach to English grammar (2nd ed.). Oxford: OUP.

17. Graver, B. D. (1986). Advanced English Practice (2nd ed.). Oxford: OUP.

18. Ota, A. (1980). Hitei no jmi: Jmiron josersu [Semantics of negation: A prolegomenon to semantics]. Tokyo: Taishukan.

19. Searle, J. (1969). Speech act. Cambridge: Cambridge University Press.

20. Grice, H. P. (1975). Logic and conversation', in P. Cole and J. Morgan (eds) Syntax and Semantics 3: Speech Acts, New York: Academic Press.

21. Richards, L. \& Morse, J. (2002) Readme First for a User's Guide to Qualitative Methods. Thousand Oaks: Sage.

22. Cameron, D. (2016). The EU referendum. https://www.gov.uk/government/speeches/ pm-speech-at-o2-on-the-ereferendum-23-february2016

23. Hidalgo, L. (2000). Negation, text worlds, and discourse: The pragmatics of fiction. Stanford: Alex Publishing Corporation.

24. May, T. (October 9, 2017). Leaving the EU. https://www.gov.uk/government/ speeches/pm-statement-on-leaving-the-eu-9-oct2017. 